\title{
Snake Venom Proteinases as Tools in Hemostasis Studies: Structure-Function Relationship of a Plasminogen Activator Purified from Trimeresurus stejnegeri Venom
}

\author{
A. Wisner S. Braud C. Bon \\ Unité des Venins, Institut Pasteur, Paris, France
}

\section{Key Words}

Snake venom - Proteinase - Plasminogen activator - Structure-function - Haemostasis

\begin{abstract}
Snake venom serine proteinases affect many steps of the blood coagulation cascade. Each of them usually acts selectively on one coagulation factor. They are therefore potentially useful components to study the mechanisms of action, the regulation and the structurefunction relationships of human serine proteinase coagulation factors. This strategy is illustrated for a plasminogen activator purified from Trimeresurus stejnegeri venom.
\end{abstract}

Copyright $@ 2002$ S. Karger AG, Basel

\section{Serine Proteinase Family}

Serine proteinases are found in microorganisms [1], plants [2] and numerous animals $[3,4]$. These enzymes share many biochemical and structural properties, such as a catalytic triad (Ser ${ }^{195}$, His $^{57}$, Asp ${ }^{102}$ ), the main criterion for classification of a protein as a serine proteinase. They exhibit structural differences which can be used to classify this family into three subgroups: trypsin-like, subtilisinlike and carboxypeptidase-like serine proteinase [3].

\section{Human Serine Proteinases Involved in}

\section{Hemostasis}

Human serine proteinases have diverse functions and may be involved in digestion, complement activation, cellular differentiation and hemostasis [3]. In particular, human trypsin-like serine proteinases are involved in

\footnotetext{
Dr. Cassian Bon

Head of the Venoms Unit, Institut Pasteur

25-28, rue du Docteur-Roux

F-75724 Paris Cedex 15 (France)

Tel. +3314568 86 85, Fax +33140613057, E-Mail cbon@pasteur.fr
} 
hemostasis, with roles in platelet aggregation, coagulation and fibrinolysis (fig. 1). Their activity is regulated by various families of inhibitors, notably the serine proteases inhibitors (serpins), which slowly form irreversible complexes with the protease.

Human serine proteinases active in hemostasis generally contain at least a catalytic domain structurally similar to trypsin. Some also possess, at their N-terminal end, one or several additional domains (kringle, apple, finger or epidermal growth factor domains) that are involved in protease interactions with cofactors and cellular receptors. Alignments of the amino acid sequences of their catalytic domain show insertions at the variable regions, which are involved in the interaction of the serine proteinases with their macromolecular substrates, and/or specific inhibitors, as demonstrated by site-directed mutagenesis studies [5-8].

The crystal structures of more than twenty trypsin-like serine proteinases have been determined. They include those of bovine chymotrypsin [9], bovine trypsin [10], porcine kallikrein [11], human thrombin [12] and the catalytic domains of human factor X [13] and human tissue-type plasminogen activator (tPA) [14]. The overall structure of serine proteinases is highly conserved in all members of the family $[15,16]$, since they are all folded into two six-stranded $\beta$-barrels, separated by the catalytic residues, and a C-terminal helical segment. In trypsin-like serine proteinases, the $S_{1}$ pocket is highly conserved, particularly the aspartate residue at position 189, which forms a canonical ion pair interaction with the positively charged side chain of the $\mathrm{P}_{1}$ residue of the substrate molecule [17].

However, there are still major unanswered questions concerning the structure of the human serine proteinases involved in hemostasis. These questions mainly concern the dynamics of activation of the zymogen in potent enzymes, inhibition by physiological inhibitors and the molecular effects of these enzymes on their protein targets. To characterize the structural elements involved in target molecule recognition, snake venom trypsinlike serine proteases provide excellent models.

\section{Snake Venom Serine Proteinases Affecting \\ Hemostasis}

Serine proteinases are very abundant in Viperidae and Crotalidae venoms in which they may account for $20 \%$ of the total protein content. They are not lethal by themselves, but they contribute to the toxic effect of the venom when associated with other venom proteins. They selectively affect many steps in the blood coagulation cascade by the activation or the inhibition of specific blood factors involved in platelet aggregation, coagulation or fibrinolysis (fig. 1) [18-20].

Various snake venom serine proteinases have a platelet-aggregating activity. The mechanism of action of MSP1 (Bothrops moojeni), cerastobin (Cerastes vipera), cerastocytin and cerastotin (Cerastes cerastes) on platelet activation is unknown [21,22], but it has been reported that thrombocytin (Bothrops atrox) and $\mathrm{PA}-\mathrm{Bj}$ (Bothrops jararaca) activate proteinase-activated receptors 1 and 4 of thrombin (PAR-1 and PAR-4) in human blood platelets $[23,24]$. Other snake venom serine proteinases affect coagulation factors. A coagulant factor from Russell's viper venom (RVV-V), selectively activates factor $\mathrm{V}$, converting it to FVa by cleaving a single peptide bond [25]. An anticoagulant enzyme from Agkistrodon contortrix contortrix venom activates protein C (ACC-C) [26]. The resulting activated protein $\mathrm{C}$ then degrades factor $\mathrm{Va}$ and factor VIIIa, resulting in an anticoagulant effect. Many other Viperidae serine proteinases convert fibrinogen into fibrin by cleaving fibrinopeptides A and/or B [27-29]. 
a

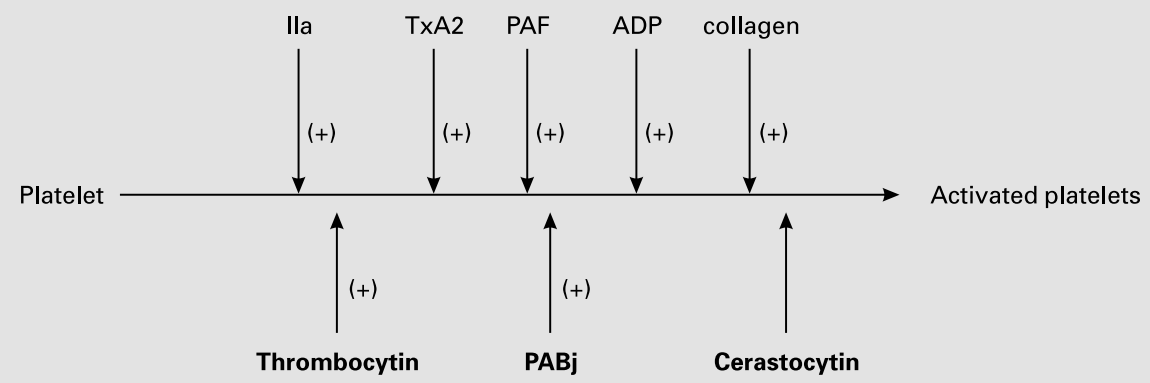

b
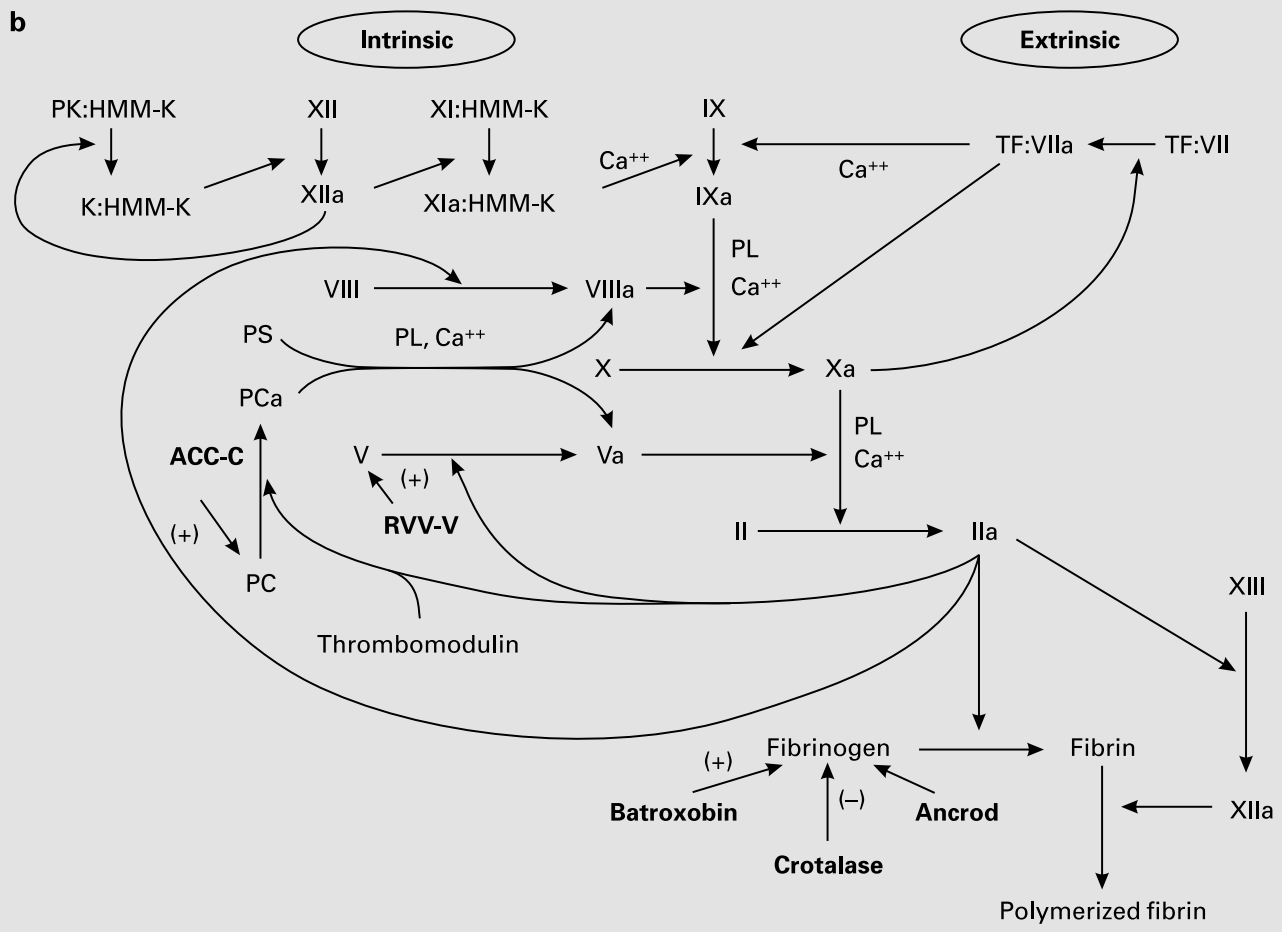

c
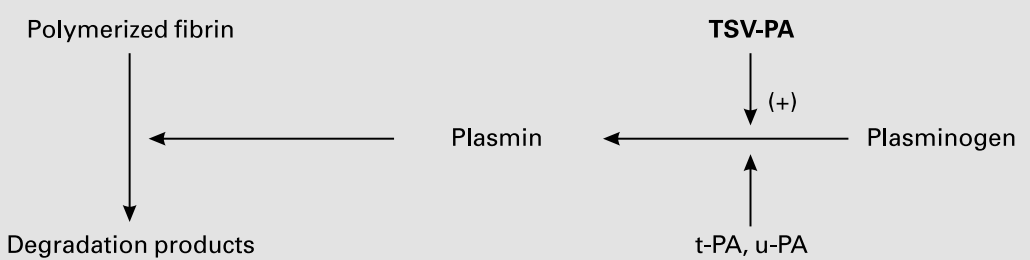

Fig. 1. Physiological processes of hemostasis. Action of various snake venom serine proteinases on the three pathways of hemostasis: platelet aggregation (a), coagulation (b) and fibrinolysis (c). Snake venom serine proteinases are in bold. 
As this activity resembles the most wellknown activity of thrombin, these venom components are generally termed 'thrombinlike' enzymes. However, the fibrin monomers generated by venom thrombin-like enzymes undergo limited polymerization, because only one fibrinopeptide is generally cleaved and because these enzymes do not activate factor XIII, to generate factor XIIIa. The clot is stabilized as the factor XIIIa catalyzed crosslinking of fibrin monomers. Many snake venom enzymes share one or several, but not all, the activities of human thrombin. They are therefore interesting tools for investigating the various activities of this multifunctional enzyme. On the other hand, Trimeresurus stejnegeri venom plasminogen activator (TSV-PA) is the first serine proteinase from snake venom reported to activate fibrinolysis [30].

Snake venom serine proteinases like the human serine proteinases affecting hemostasis belong to the trypsin-like subfamily. Alignments of the sequences of these proteinases with the catalytic domains of human serine proteinases highlight the presence of restricted variable regions in the snake venom enzymes (fig. 2). The restriction of these regions in snake venom serine proteinases probably accounts for their resistance to physiological inhibitors and raises interesting questions concerning their substrate specificity. They also display high levels of sequence identity, despite having different but specific physiological properties.

The crystallographic structure of a snake venom serine proteinase (TSV-PA) was determined [31]. Detailed analysis of the threedimensional structure of TSV-PA indicates that access to the active site is restricted to the west by a loop segment. This loop has one more amino acid in TSV-PA than in trypsin, at position 218 , and a proline is present in a cis conformation at position 219. The main chain of this loop has a conformation similar to that of the ancestral molecule, glandular kallikrein, which shows $36.5 \%$ identity to TSV-PA at the amino acid sequence level. The kallikrein loop also has an additional amino acid, at position 218, and a cis $\operatorname{Pro}^{219}$ [11], consistent with the proposed evolution of TSV-PA from glandular kallikrein [3234].

\section{Structure-Function Study of TSV-PA: An Approach to New Thrombolytic Agents}

Since thrombotic disorders remain a major cause of morbidity and mortality in many countries, studies on the fibrinolytic system, which uniquely counterbalances the blood coagulation cascade, have called for intense research efforts [35-37] The rate-limiting step in fibrinolysis is catalyzed by t-PA, a member of the serine proteinase family which converts plasminogen into an active proteinase plas$\min [37]$. The specificity of t-PA for plasminogen, which has been attributed to its simultaneous binding to fibrin through its kringle domains [38], is in fact an inherent property of its protease domain since it is maintained in the absence of fibrin $[39,40]$. On the other hand, recent structural investigations confirm the close similarity of the t-PA proteinase

Fig. 2. Sequence alignments. The amino acid sequences of batroxobin [43], Ancrod [44], TSV-PA [30], RVV-V [45], porcine glandular kallikrein [11], human t-PA [14] and bovine chymotrypsin [46] were aligned according to their topological equivalence. The numbering refers to chymotrypsinogen. Residues of the catalytic triad are marked by stars. Particularly close sequence homologies between all seven proteins are given in pale gray boxes, where identities are typed in dark gray. The figure was prepared using the Clustal W program. 


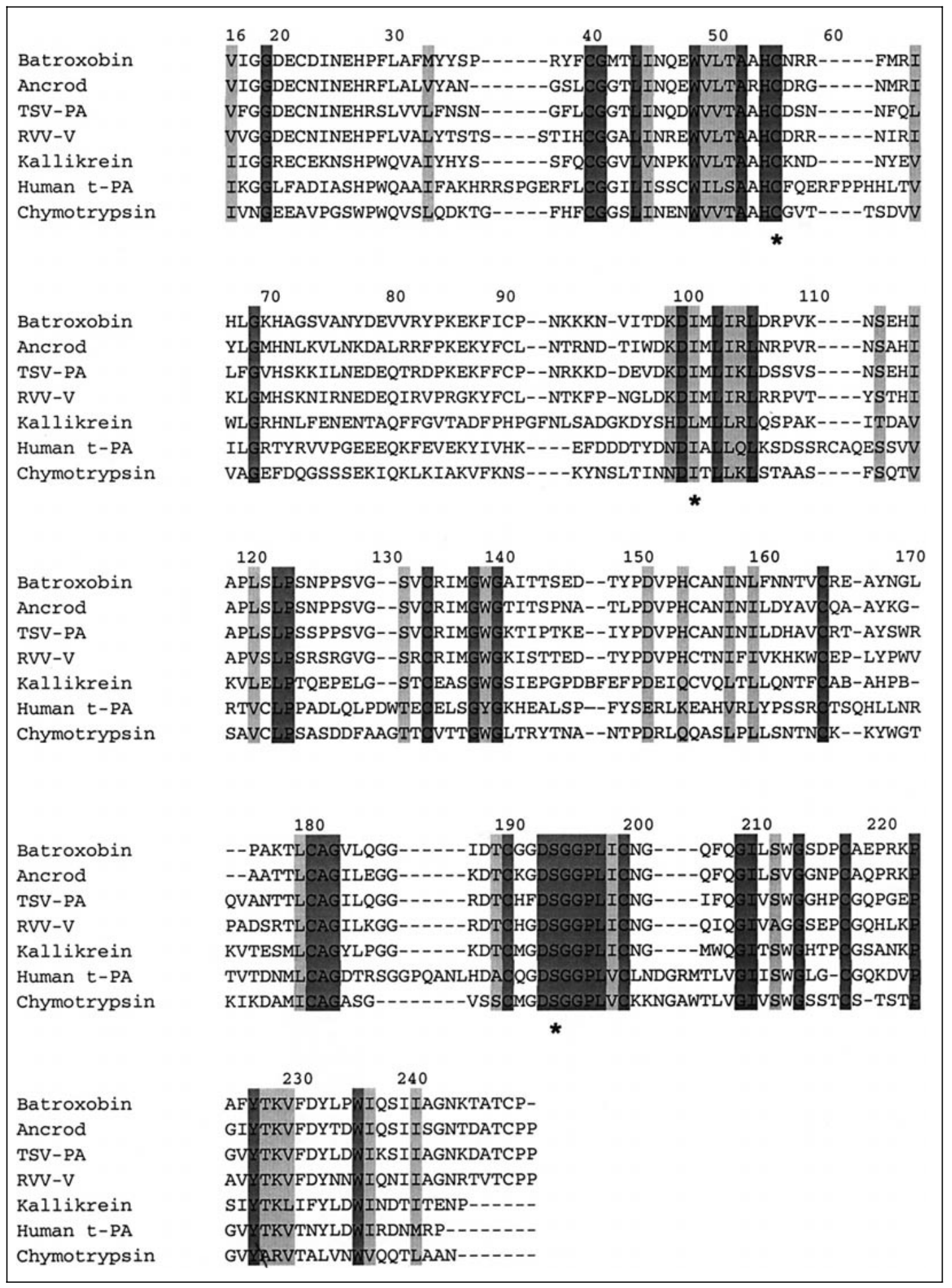

Snake Venom Proteinases as Tools in

Haemostasis 2001:31:133-140 
domain to that of nonspecific proteinases such as trypsin [14, 16]. Nevertheless, the molecular basis for the specificity of t-PA for plasminogen remains poorly understood. TSV-PA, which like t-PA, selectively converts plasminogen into plasmin by cleavage of the peptide bond $\mathrm{Arg}^{561} \mathrm{Val}^{562}$, is a useful structural template for the identification of the site of interactions of these proteins with plasminogen and the plasminogen activator inhibitor1 (PAI-1).

Although TSV-PA shares only $23 \%$ sequence identity with the catalytic domain of t-PA, its tridimensional structure demonstrates a close structural similarity to t-PA [31]. Close to its active site, TSV-PA possesses the 99-loop which projects from the molecular surface and forms a highly charged rim (Lys ${ }^{94}$ Lys $^{95}$-Asp ${ }^{96}-\mathrm{Asp}^{97}$-Glu $^{98}{ } \mathrm{Val}^{99}$ ). A salt bridge between $\mathrm{Asp}^{97}$ and $\mathrm{Arg}^{174}$ stabilizes this loop and occludes the $\mathrm{S}_{4}$ binding pocket. The replacement of the sequence Asp ${ }^{96}-\mathrm{Asp}^{97}{ }_{-} \mathrm{Glu}^{98}$ to Asn-Val-Ile resulted in a loss of plasminogenolytic activity, indicating the key role this sequence plays in substrate recognition by the enzyme. Separate replacement of each of these negatively charged residues at the site indicated that $\mathrm{Asp}^{97}$ was the most critical residue. The Asp ${ }^{97}$-Val point mutation resulted in a 125-fold decrease in TSV-PA activity for plasminogen activation [41]. Mutational studies around the segment 172-176, however, have shown little or no effect on the plasminogenolytic activity of TSV-PA. It is therefore reasonable to assume that Asp ${ }^{97}$ changes its conformation upon complex formation and participates in secondary contacts with plasminogen. The conservation of $\mathrm{Asp}^{97}$ in urokinase-type PA (u-PA) and t-PA is noteworthy. It is likely that $\mathrm{Asp}^{97}$ of t-PA and uPA have a similar role in plasminogen recognition.

The ability of a serpin to neutralize a given serine proteinase appears to depend both upon the sequence of its reactive center loop and the contribution of one (or more) secondary binding site(s). TSV-PA escapes some serpins by the use of at least two molecular mechanisms: the first involves $\mathrm{Phe}^{193}$, a residue of the catalytic groove, the second originates from the absence of secondary binding sites as positively charged residues in the variable region-1 (VR1) of TSV-PA. While all other trypsin-like proteinases have a glycine at position 193 in the chymotrypsin numbering system, TSV-PA has a phenylalanine, and this phenylalanine restricts access to the $\mathrm{S}^{\prime} 2$ pocket. The TSV-PA mutant (F193G), in which Phe ${ }^{193}$ had been replaced by a glycine, was inhibited by PAI-1, $\alpha_{2}$-antiplasmin and $\alpha_{1}$ antitrypsin with association rate constant (kon) values at least twenty-fold higher than for the wild-type enzyme. On the other hand, substitution of the VR1 of TSV-PA for either that of t-PA or u-PA also increased the kon value for the inhibition by PAI-1 over hundred times. Mutations were additive, for the inhibition by PAI-1: the double TSV-PA variant F193G/t-PA (VR1) was inhibited with a kon value 4 orders of magnitude higher than the wild-type enzyme. We conclude that these two motifs of TSV-PA fully account for its resistance to PAI-1. This opens the doors to therapeutic improvement of presently used fibrinolytic agents, since construction of a tPA variant containing a Phe at position 193 could give a new thrombolytic agent with a longer half-life since it resists longer to PAI-1 not only in systemic circulation but also at the clot site [42]. Moreover, the TSV-PA variant F193G is a good candidate for the crystallographic resolution of a complex between a proteinase and a serpin since it produces SDSstable complexes with PAI- $1, \alpha_{2}$-AP and $\alpha_{1}$ AT. Indeed, the accession of this kind of complex could improve our understanding of the inhibitory mechanism of serpins. 


\section{References}

1 Siezen RJ: Multi-domain, cell-envelope proteinases of lactic acid bacteria. Antonie Van Leeuwenhoek 1999;76:139-155.

2 Rudenskaya GN, Bogdanova EA, Revina LP, Golovkin BN, Stepanov VM: Macluralisin - a serine proteinase from fruits of Maclura pomifera (Raf.). Schneid Planta 1995;196: 174-179.

3 Neurath H: Evolution of proteolytic enzymes. Science 1984;224:350357.

4 Neurath H: Proteolytic enzymes, past and present. Fed Proc 1985;44: 2907-2913.

5 DiBella EE, Scheraga HA: Thrombin specificity: Further evidence for the importance of the beta-insertion loop and Trp96. Implications of the hydrophobic interaction between Trp96 and Pro60B Pro60C for the activity of thrombin. J Protein Chem 1998;17:197-208.

6 Hedstrom L, Szilagyi L, Rutter WJ: Converting trypsin to chymotrypsin: The role of surface loops. Science 1992;255:1249-1253.

7 Le Bonniec BF, Guinto ER, MacGillivray RT, Stone SR, Esmon CT: The role of thrombin's Tyr-Pro-ProTrp motif in the interaction with fibrinogen, thrombomodulin, protein $\mathrm{C}$, antithrombin III, and the Kunitz inhibitors. J Biol Chem 1993;268:19055-19061.

8 Madison EL, Goldsmith EJ, Gerard RD, Gething MJ, Sambrook JF: Serpin-resistant mutants of human tissue-type plasminogen activator. Nature 1989;339:721-724.

9 Matthews BW, Sigler PB, Henderson R, Blow DM: Three-dimensional structure of tosyl-alpha-chymotrypsin. Nature 1967;214:652-656.

10 Ruhlmann A, Kukla D, Schwager P, Bartels K, Huber R: Structure of the complex formed by bovine trypsin and bovine pancreatic trypsin inhibitor. Crystal structure determination and stereochemistry of the contact region. J Mol Biol 1973;77:417436.

11 Bode W, Chen Z: The X-ray structures of porcine pancreatic kallikrein and of its complex with bovine pancreatic trypsin inhibitor. Adv Exp Med Biol 1983;156:289-308.
12 Bode W, Mayr I, Baumann U, Huber R, Stone SR, Hofsteenge J: The refined $1.9 \AA$ A crystal structure of human alpha-thrombin: Interaction with $D$-Phe-Pro-Arg chloromethylketone and significance of the TyrPro-Pro-Trp insertion segment. EMBO J 1989;8:3467-3475.

13 Padmanabhan K, Padmanabhan $\mathrm{KP}$, Tulinsky A, Park CH, Bode W, Huber R, Blankenship DT, Cardin $\mathrm{AD}$, Kisiel W: Structure of human des(1-45) factor Xa at $2.2 \AA$ resolution. J Mol Biol 1993;232:947-966.

14 Lamba D, Bauer M, Huber R, Fischer S, Rudolph R, Kohnert U, Bode W: The 2.3 angstrom crystal structure of the catalytic domain of recombinant two-chain human tissue-type plasminogen activator. J Mol Biol 1996:258:117-135.

15 Greer J: Comparative modeling methods: Application to the family of the mammalian serine proteases. Proteins 1990;7:317-334.

16 Perona JJ, Craik CS: Structural basis of substrate specificity in the serine proteases (Review). Protein Sci 1995:4:337-360.

17 Perona JJ, Craik CS: Evolutionary divergence of substrate specificity within the chymotrypsin-like serine protease fold. J Biol Chem 1997; 272:29987-29990.

18 Kini RM, Evans HJ: Effects of snake venom proteins on blood platelets. Toxicon 1990;28:1387-1422.

19 Markland FS Jr: Snake venoms. Drugs 1997;3:1-10.

20 Mitrakul C: Effect of five Thai snake venoms on coagulation, fibrinolysis and platelet aggregation. Southeast Asian J Trop Med Public Health 1979;10:266-275.

21 Marrakchi N, Zingali RB, Karoui H, Bon C, el Ayeb M: Cerastocytin, a new thrombin-like platelet activator from the venom of the Tunisian viper Cerastes cerastes. Biochim Biophys Acta 1995;1244:147-156.

22 Serrano SM, Mentele R, Sampaio CA, Fink E: Purification, characterization, and amino acid sequence of a serine proteinase, PA-BJ, with platelet-aggregating activity from the venom of Bothrops jararaca. Biochemistry 1995;34:7186-7193.
23 Kirby EP, Niewiarowski S, Stocker K, Kettner C, Shaw E, Brudzynski TM: Thrombocytin, a serine protease from Bothrops atrox venom. 1. Purification and characterization of the enzyme. Biochemistry $1979 ; 18$ : 3564-3570.

24 Santos ABF, Serrano SMT, Kuliopulos A, Niewiarouski S: Interaction of viper venom serine peptidases with thrombin receptors on human platelets. FEBS Lett 2000;477:199202.

25 Kisiel W: Molecular properties of the factor $\mathrm{V}$-activating enzyme from Russell's viper venom. J Biol Chem 1979;254:12230-12234.

26 Stocker K, Fischer H, Meier J, Brogli M, Svendsen L: Characterization of the protein $\mathrm{C}$ activator Protac from the venom of the southern copperhead (Agkistrodon contortrix) snake. Toxicon 1987;25:239-252.

27 Pirkle H, Theodor I: Thrombin-like venom enzymes: Structure and function. Adv Exp Med Biol 1990; 281:165-175.

28 Pirkle H: Thrombin-like enzymes from snake venoms: An updated in ventory. Scientific and Standardization Committee's Registry of Exogenous Hemostatic Factors. Thromb Haemost 1998:79:675-683.

29 Stocker K, Fischer H, Meier J: Thrombin-like snake venom proteinases. Toxicon 1982;20:265-273.

30 Zhang Y, Wisner A, Xiong Y, Bon $\mathrm{C}$ : A novel plasminogen activator from snake venom. Purification, characterization, and molecular cloning. J Biol Chem 1995;270: 10246-10255.

31 Parry MA, Jacob U, Huber R, Wisner A, Bon C, Bode W: The crystal structure of the novel snake venom plasminogen activator TSV-PA: A prototype structure for snake venom serine proteinases. Structure 1998;6: 1195-1206.

32 Nakashima K, Ogawa T, Oda N, Hattori M, Sakaki Y, Kihara H, Ohno M: Accelerated evolution of Trimeresurus flavoviridis venom gland phospholipase A2 isozymes. Proc Natl Acad Sci USA 1993;90: 5964-5968. 
33 Nakashima K, Nobuhisa I, Deshimaru M, Nakai M, Ogawa T, Shimohigashi Y, Fukumaki Y, Hattori M, Sakaki Y, Hattori S: Accelerated evolution in the protein-coding regions is universal in Crotalinae snake venom gland phospholipase A2 isozyme genes. Proc Natl Acad Sci USA 1995;92:5605-5609.

34 Ogawa T, Oda N, Nakashima K, Sasaki H, Hattori M, Sakaki Y, Kihara $\mathrm{H}$, Ohno $\mathrm{M}$ : Unusually high conservation of untranslated sequences in cDNAs for Trimeresurus flavoviridis phospholipase A2 isozymes. Proc Natl Acad Sci USA 1992;89:8557-8561.

35 Collen D: On the regulation and control of fibrinolysis. Edward Kowalski Memorial Lecture. Thromb Haemost 1980;43:77-89.

36 Collen D, Lijnen HR, Todd PA, Goa KL: Tissue-type plasminogen activator. A review of its pharmacology and therapeutic use as a thrombolytic agent. Drugs 1989;38:346388.

37 Collen D, Lijnen HR: Basic and clinical aspects of fibrinolysis and thrombolysis. Blood 1991;78:31143124.
38 Lijnen HR, Collen D: Molecular interactions between tissue-type plasminogen activator and plasminogen. Methods Enzymol 1993;223: 197-206.

39 Kohnert U, Hellerbrand K, Martin U, Stern A, Popp F, Fischer S: The recombinant Escherichia coli-derived protease-domain of tissuetype plasminogen activator is a potent and fibrin specific fibrinolytic agent. Fibrinolysis 1996;10:93-102.

40 Martin U, Kohnert U, Stern A, Popp F, Fischer S: Comparison of the recombinant Escherichia coliproduced protease domain of tissuetype plasminogen activator with alteplase, reteplase and streptokinase in a canine model of coronary artery thrombolysis. Thromb Haemost 1996;76:1096-1101.

41 Zhang Y, Wisner A, Maroun RC, Choumet V, Xiong Y, Bon C: Trimeresurus stejnegeri snake venom plasminogen activator. Site-directed mutagenesis and molecular modeling. J Biol Chem 1997;272:2053120537.
42 Shohet RV, Spitzer S, Madison EL, Bassel-Duby R, Gething MJ, Sambrook JF: Inhibitor-resistant tissuetype plasminogen activator: An improved thrombolytic agent in vitro. Thromb Haemost 1994;71:124128.

43 Itoh N, Tanaka N, Mihashi S, Yamashina I: Molecular cloning and sequence analysis of cDNA for batroxobin, a thrombin-like snake venom enzyme. J Biol Chem 1987; 262:3132-3135.

$44 \mathrm{Au}$ LC, Lin SB, Chou JS, Teh GW, Chang KJ, Shih CM: Molecular cloning and sequence analysis of the cDNA for ancrod, a thrombin-like enzyme from the venom of Calloselasma rhodostoma. Biochem J 1993. 294(pt 2):387-390.

45 Tokunaga $F$, Nagasawa K, Tamura $\mathrm{S}$, Miyata $\mathrm{T}$, Iwanaga $\mathrm{S}$, Kisiel W: The factor $\mathrm{V}$-activating enzyme (RVV-V) from Russell's viper venom. Identification of isoproteins RVV-V alpha, -V beta, and -V gamma and their complete amino acid sequences. J Biol Chem 1988;263: 17471-17481.

46 Wang D, Bode W, Huber R: Bovine chymotrypsinogen A X-ray crystal structure analysis and refinement of a new crystal form at $1.8 \AA$ resolution. J Mol Biol 1985;185:595-624. 